\title{
144. Incorporation of Labelled Sulfate into Porphyra tenera and the Distribution of Sulfur in the Chromopeptides Isolated from Phycoerythrin
}

\author{
By Teruko FuJiwara \\ Kobe Yamate Women's College, Kobe \\ (Comm. by Shiro AкAвori, M.J.A., Sept. 12, 1967)
}

During investigations on the chemical structure of the chromoproteins in Porphyra tenera, it was demonstrated that, one of them, phycoerythrin, yielded several chromopeptides on proteolytic degradation. These chromopeptides possessed unidentified sulfur containing moieties besides carbohydrate and peptide fragments close to the chromophore group which could not be attributed to the sulfurcontaining amino acids in the peptides. ${ }^{1)-5)}$

To investigate these unidentified sulfur moieties close to the chromophore group, the incorporation of labelled sulfate into phycoerythrin was studied. Although most algae, like other microorganisms and higher plants, can utilize sulfate as their sole source of sulfur, the mechanism of reduction of sulfate in marine algae seems not yet be clarified in detail. There are only a few reports on salfate reduction in algae. ${ }^{6)-9)}$ For the purpose to solve the problems concerned with the unidentified sulfurs mentioned above and those involved in the reducing process of the sulfate, in preliminary studies, the incorporation of labelled sulfate into the fronds of Porphyra tenera, especially, into the phycoerythrin were studied by the following design. ${ }^{10}$ Growing fronds of Porphyra tenera in natural sea water containing Provasoli's metal mixture ${ }^{11}$ and $\mathrm{H}_{2}{ }^{35} \mathrm{SO}_{4}$ (0.1-1 mc. $/ 1$ of culture medium) were incubated for 60-72 hr. under a fluorescent light of $6000 \mathrm{lux}$ at $11-15^{\circ} \mathrm{C}$.

1. Incorporation of ${ }^{35} \mathrm{~S}$ into Porphyra tenera.

After incubation, the fronds were centrifuged to eliminate the residue of the culture medium, and washed with water, then frozen at $-20^{\circ} \mathrm{C}$. The water extracts of frozen fronds were fractionated into four fractions, namely, proteins (Frac. II), cold and hot water soluble polysaccharides (Frac. III and IV, respectively), and cell walls (Frac. V) as described in the text in Table I. The radioactivity of the fractions was determined as $\mathrm{Ba}^{35} \mathrm{SO}_{4}$ which was precipitated by Pirie's method. ${ }^{12}$ ) The radioactivity of all sample was measured at infinite thinness in a Nucleo Chicago gas flow counter. Significant radioactivity was found in polysaccharides (Frac. III and IV) and 
Table I. Incorporation of ${ }^{35} \mathrm{~S}$ into Porphyra tenera

\begin{tabular}{c|cc}
\hline \multirow{2}{*}{ Fraction $^{\mathrm{b})}$} & Radioactivity of ${ }^{35} \mathrm{~S}(\text { counts } / \mathrm{min} / 10 \mathrm{mg} \text {. dry wt. })^{\mathrm{a})}$ \\
\cline { 2 - 3 } & Experiment 1 & Experiment 2 \\
\hline I & 3496 & 3066 \\
II & - & 2389 \\
III & 1554 & 1180 \\
IV & 7215 & 6075 \\
V & 1200 & 1140 \\
\hline
\end{tabular}

a) Radioactivity was determined as $\mathrm{Ba}^{35} \mathrm{SO}_{4}$ by Pirie's method. ${ }^{12}$ )

b) Fractionation was carried out as follows: Fronds were cultivated, frozen, homogenized, and extracted twice with $\mathrm{M} / 10$ phosphate buffer, $\mathrm{pH} 6.5$ for 3 days at $5{ }^{\circ} \mathrm{C}$. The extract was adjusted to $60 \%$ of ammonium sulfate, then centrifuged. The precipitate (Frac. I) was dialyzed against distilled water to remove salt. Fraction I was treated with $15 \%$ saturation of ammonium sulfate and precipitate (Frac. II) was dialyzed against distilled water. The supernatant after treatment with $60 \%$ saturation of ammonium sulfate from the first estract was dialyzed against distilled water to remove salt (Frac. III). The residue of the fronds was extracted with hot water,and the extract was concentrated in vacuo (Frac. IV). Fraction $\mathrm{V}$ was the residue after extraction with hot water.

proteins (Frac. II) and cell walls (Frac. V), as shown in Table I. A large proportion of the radioactivity was found in the hot soluble polysaccharides (Frac. IV).

2. Incorporation of ${ }^{35} \mathrm{~S}$ into chromoproteins.

Pure labelled phycoerythrin and phycocyanin were prepared as reported previously. ${ }^{13}$ The radioactivities of both proteins were determined after desalting with Sephadex G25. The distribution of the radioactivity in the two proteins is given in Table II.

Table II. Incorporation of ${ }^{35} \mathrm{~S}$ into chromoproteins in Porphyra tenera

\begin{tabular}{llc}
\hline \multicolumn{1}{c}{ Fraction $^{\mathrm{b})}$} & \multicolumn{1}{c}{$\begin{array}{c}\text { Radioactivity } \\
\text { (counts/min/10 mg. dry wt.) }\end{array}$} \\
\hline Phycoerythrin & $1062^{\mathrm{c})}$ & $21,050^{\mathrm{d}}$ ) \\
& 1010 & 23,620 \\
Phycocyanin & - & \\
Water soluble polysaccharide & 704 & \\
Residue & 2340 & 2550 \\
\hline
\end{tabular}

a) Radioactivity was determined as $\mathrm{Ba}^{35} \mathrm{SO}_{4}$ by Pirie's method. ${ }^{12}$ )

b) Phycoerythrin and phycocyanin were prepared as described previously. ${ }^{13)}$ Preparation of water soluble polysaccharides is described in Table I. The residue was extracted with $\mathrm{M} / 10$ phosphate buffer, $\mathrm{pH} 6.5$.

c) Data from experiment in 1965 .

d) Data from experiment in 1966 .

The results in Tables I and II show that sulfate serves as the sole sulfur source for growth of Porphyra tenera, and confirm the 
incorporation of ${ }^{35} \mathrm{~S}$ into the chromoproteins. The contents of labelled sulfur in the two proteins, phycoerythrin and phycocyanin coincided fairly well with their sulfur contents measured by elemental analysis in the range of $1.57-1.76 \%$ and $1.60-1.69 \%$, respectively ${ }^{14), 15)}$ (see Table IV).

3. Distribution of ${ }^{35} \mathrm{~S}$ in chromopeptides obtained from phycoerythrin by proteolytic degradation.

Labelled phycoerythrin was hydrolyzed with pepsin and then pronase (Streptomyces griseus proteinase) and fractionated as shown in Scheme 1 according to the method reported previously. ${ }^{2}$ The radioactivities of the three chromopeptides fractions, chromopeptide-I, II, and B obtained were examined and, the results are summarized in Table III. Three experiments, Experiments-1, 2, and 3, were made in 1964, 1965, and 1966, respectively. The results of these

Scheme 1

Preparation of chromopeptides from Phycoerythrin ${ }^{2}$

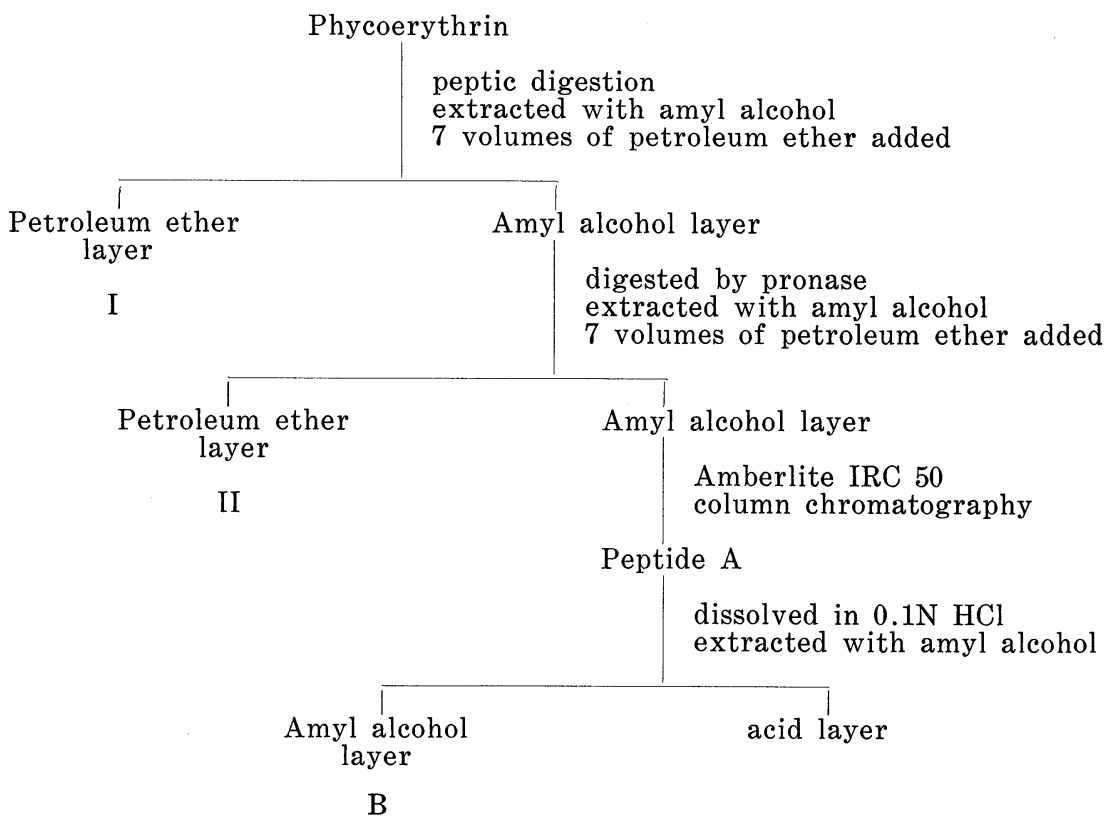

three experiments, given in Table III, show that there is significant incorporation of ${ }^{35} \mathrm{~S}$ into the chromopeptides.

As reported previously, ${ }^{2)}$ these chromopeptides possessed no amino acid sulfur. Therefore, the unidentified sulfur atoms in the chromopeptides will be in the form of sugar sulfate ester, because these chromopeptides with low nitrogen contents seem to contain carbohydrate, as shown in Table IV. In fact, xylose, arabinose and 
Table III. Distribution of ${ }^{35} \mathrm{~S}$ in chromopeptides obtained from Phycoerythrin by proteolytic hydrolysis

\begin{tabular}{|c|c|c|c|}
\hline Fraction & Experiment 1 & $\begin{array}{c}\text { Radioactivity } \\
\text { (counts/min/mg. nitrogen) } \\
\text { Experiment } 2\end{array}$ & Experiment 3 \\
\hline Phycoerythrin & 950 & 1062 & 2578 \\
\hline Chromopeptide I & 328 & 353 & \\
\hline Chromopeptide II & 399 & 159 & \\
\hline Chromopeptide B & 1333 & 1215 & 2830 \\
\hline
\end{tabular}

galactose were found in the chromopeptides as reported previously. ${ }^{3,4)}$ On hydrolyzing labelled chromopeptide-I with mild acid $(0.25 \mathrm{~N} \mathrm{HCl}$ at $100^{\circ} \mathrm{C}$ for $5 \mathrm{hr}$.), some ${ }^{35} \mathrm{SO}_{4}^{--}$was solublized, while some remained in the residue, as shown in Table V.

Table IV. Elemental analysis and minimum molecular weight of chromopeptides derived from phycoerythrin by proteolytic hydrolysis ${ }^{2)}$

\begin{tabular}{lcccccc}
\hline & $\mathrm{C}$ & $\mathrm{H}$ & $\mathrm{N}$ & $\mathrm{S}$ & $\mathrm{S}: \mathrm{N}$ & MW $^{\mathrm{a}}$ \\
\hline Phycoerythrin & 50.80 & 7.99 & 15.13 & $1.72^{\mathrm{b})}$ & $1: 9$ & \\
Chromopeptide B & 51.78 & 6.56 & 5.34 & 1.30 & $1: 9$ & 2.460 \\
Chromopeptide I & & & & & & \\
$\quad$ P 11a & 53.37 & 6.61 & 5.20 & 0.67 & $1: 18$ & 4.795 \\
P 11b & 50.60 & 6.94 & 5.89 & 1.65 & $1: 9$ & 1.945 \\
P 12a & 39.86 & 4.82 & 6.04 & 1.45 & $1: 9$ & \\
& 39.04 & $4.78)$ & & 1.49 & & 2.145 \\
\hline
\end{tabular}

a) Minimum molecular weight calculated for 1.0 mole of sulphur.

b) Tin-strong phosphoric reduction method. ${ }^{14)}$

On hydrolyzing labelled chromopeptide-B with $0.08 \mathrm{~N} \mathrm{HCl}$ at $100^{\circ} \mathrm{C}$ for $1.5 \mathrm{hr}$., no release of ${ }^{35} \mathrm{SO}_{4}^{--}$was observed, while with $0.25 \mathrm{~N} \mathrm{HCl}$ at $100^{\circ} \mathrm{C}$ for 0.5 or $3.0 \mathrm{hr}$., release of ${ }^{35} \mathrm{SO}_{4}^{--}$was observed. In the two latter cases, some radioactivity was detected in the residue of chromopeptide-B after hydrolysis (Table VI). These results show that after hydrolysis, $40 \%$ of the radioactivity is in the form of sulfate and $60 \%$ in the residue of both chromopeptide-I and B.

Table V. Mild acid hydrolysis of ${ }^{35} \mathrm{~S}$ labelled chromopeptide I $\left(0.24 \mathrm{~N} \mathrm{HCl}\right.$ at $100^{\circ} \mathrm{C}$ for $5 \mathrm{~h}$. $)$

\begin{tabular}{|c|c|c|}
\hline Fraction & $\begin{array}{c}\text { Radioactivity*) } \\
\text { (counts/min/mg. N) }\end{array}$ & ratio \\
\hline Before hydrolysis & 353 & 1.00 \\
\hline $\begin{array}{l}{ }^{35} \mathrm{SO}_{4}^{--} \text {released with } \\
\text { acid hydrolysis }\end{array}$ & 162 & 0.44 \\
\hline Residue & 208 & 0.56 \\
\hline
\end{tabular}

*) Radioactivity measured by $\mathrm{Ba}^{35} \mathrm{SO}_{4}$ precipitation. ${ }^{12)}$ 
Table VI. Mild acid hydrolysis of ${ }^{35} \mathrm{~S}$ labelled chromopeptide B by varied procedure

\begin{tabular}{|c|c|c|c|c|}
\hline \multirow{2}{*}{ Hydrolysis } & \multicolumn{4}{|c|}{ Radioactivity (counts/min/mg. N) } \\
\hline & ${ }^{35} \mathrm{SO}_{4}^{--}$Released & (ratio) & Residue & (ratio) \\
\hline $0.08 \mathrm{~N} \mathrm{HCl}, 1.5 \mathrm{~h}$. & 0 & $(0)$ & 192 & $(1.00)$ \\
\hline $0.25 \mathrm{~N} \mathrm{HCl}, 0.5 \mathrm{~h}$. & 67 & $(0.37)$ & 112 & $(0.63)$ \\
\hline $0.25 \mathrm{~N} \mathrm{HCl}, 3.0 \mathrm{~h}$. & 71 & $(0.36)$ & 125 & $(0.64)$ \\
\hline
\end{tabular}

Recently, Rees ${ }^{16)}$ and Turvey et al.$^{17)}$ pointed out that the time $(0.1-3 \mathrm{hr}$.$) required for hydrolysis of esters by 0.25 \mathrm{~N} \mathrm{HCl}$ at $100^{\circ} \mathrm{C}$ depended on the type of sugar sulfate ester. Thus, the results shown in Tables $\mathrm{V}$ and VI, indicate that $40 \%$ of the radioactivity in the chromopeptides seems to be in the form of sugar sulfate ester, because it was involved in a labile linkage of sulfate which was hydrolyzed by mild acid.

Lloyd et al..$^{18)}$ reported that polysaccharide sulfates have characteristic infra-red absorptions at $1,240 \mathrm{~cm}^{-1}$ and $850 \mathrm{~cm}^{-1}$ which can be attributed to the $\mathrm{C}-\mathrm{O}-\mathrm{S}$ vibration. Chromopeptide-B and $\mathrm{P} 11 \mathrm{~b}$ and P12a (the products of chromopeptide-I, see Table IV) also showed characteristic infra-red absorptions at $1,240 \mathrm{~cm}^{-1}$ and $850 \mathrm{~cm}^{-1}$, respectively, as reported previously. ${ }^{2}$ ( These characteristic infra-red absorptions of the $\mathrm{C}-\mathrm{O}-\mathrm{S}$ vibration indicate that a sugar sulfate esters in present chromopeptides-I and -B. Although nature of the sugar of chromopeptide-B has not yet been determined, chromopeptide-B probably possesses a carbohydrate like that of chromopeptide-I because the two chromopeptides gave similar values on elemental analysis with the low nitrogen content of $5-6 \%$ (Table IV).

A hydrolyzate of chromopeptide-B was obtained under mild conditions $\left(0.25 \mathrm{NHCl}, 100^{\circ} \mathrm{C}, 3 \mathrm{hr}\right.$.). The sulfate was precipitated as $\mathrm{Ba}^{35} \mathrm{SO}_{4}$ and the pigment was extracted from the dried acid solution with ethanol. The pigment was subjected to paper electrophoresis ( $0.1 \mathrm{M}$ pyridine acetate buffer, $\mathrm{pH} 6.5,600 \mathrm{~V}, 5 \mathrm{~mA}$ for $2 \mathrm{hr}$.). Neither the pigment nor radioactivity migrated from the origin under the these conditions. This shows that besides sulfate some of the sulfur is firmly combined with the chromophore group. Radioautography of a two-dimentional paper chromatogram (n-butanol-acetic acidwater, $4: 2: 1, \mathrm{v} / \mathrm{v}$, and $80 \%$ of phenol $\mathrm{w} / \mathrm{w}$ with ammonia) of the acid hydrolyzate $\left(5.7 \mathrm{~N} \mathrm{HCl}, 105-110^{\circ} \mathrm{C}, 24 \mathrm{hr}\right.$.) of labelled phycoerythrin revealed two radioactive spots of unidentified substances besides those of methionine and cystine.

As previously reported, ${ }^{2)}$ phycoerythrin contains $1.7 \%$ total sulfur, composed of $0.32 \%$ methionine-S, $0.59 \%$ half cystine-S, and 
0.79\% unidentified-S..$^{2,4)}$ This unidentified-S could be involved in two types of sulfur compounds, one being sugar sulfate and the other being sulfur firmly bound to the chromophore group, probably in thioether form.

This work was supported in part by a grant for scientific research from the Ministry of Education of Japan. The author express her sincere thanks to Dr. Shiro Akabori for his continued interest for this work and to Professor F. Matsumoto and Mr. S. Sato, Hiroshima University, and Dr. S. Kawasaki and Dr. Kawai, Kyowa Hakko Ltd. for kindly supplying labelled Porphyra tenera and also to Dr. and Mrs. M. Kusunose, Osaka City University for measurement of radioactivity.

\section{References}

1) Fujiwara, T.: J. Biochem. (Japan), 44, 723 (1957).

2) —: J. Biochem. (Japan), 48, 317 (1960).

3) —: J. Biochem. (Japan), 49, 361 (1961).

4) - : Proc. 4th Int. Seaweed Symp., Brarritz, 312 (1963).

5) —: J. Biochem. (Japan), 43, 195 (1956).

6) Schiff, J. A.: Plant Physiol., 34, 73 (1959).

7) Shrift, A.: Plant Physiol., 34, 505 (1959).

8) Wedding, R. T., and Black, M. K.: Plant Physiol., 35, 72 (1960).

9) Gibbs, M., and Schiff, J. A.: Plant Physiology (F. C. Steward ed.) Vol. 1b, Academic Press, New York (1960).

10) Satō, S., Itō, K., and Matsumoto, F.: J. Fac. Fish. Anim. Husb., Hiroshima Univ., 5, 537 (1964).

11) Provasoli, L., Mclaughlin, J. J. A., and Droop, M. R.: Arch. für Mikrobiol., 25, 392 (1958).

12) Pirie, N. W.: Biochem. J., 26, 2041 (1932).

13) Fujiwara, T.: J. Biochem. (Japan), 42, 411 (1955).

14) Akabori, S., and Fujiwara, T.: Bull. Chim. Biol. (Paris), 40, 1983 (1958).

15) Kitasato, Z.: Acta Phytochim., (Japan), 2, 274 (1925).

16) Rees, D. A.: Biochem. J., 88, 343 (1963).

17) Turvey, J. R., and Rees, D. A.: Nature, 189, 831 (1961).

18) Lloyd, A. G., Dodgson, K. S., Price, R. G., and Rose, F. A.: Biochim. Biophys. Acta, 46, 108 (1961). 